\title{
A case report of non-arteritic anterior ischaemic optic neuropathy
}

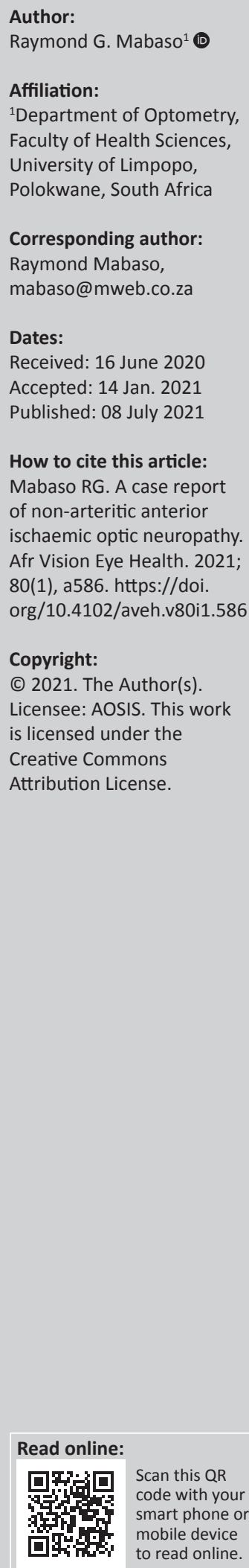

\begin{abstract}
Non-arteritic anterior ischaemic optic neuropathy (NA-AION) is a common cause of sudden, unilateral, painless vision loss in people over the age of 50 years. The purpose of this article was to report a case of NA-AION in a 56-year-old black man with reduced vision in the left eye. The patient had relative afferent pupillary defect and diffuse papilledema in the left eye, but no visual symptoms and/or associated risk factors. Correct diagnosis is essential.
\end{abstract}

Keywords: non-arteritic anterior ischaemic optic neuropathy; ischaemic optic neuropathy; optic nerve atrophy; optic disc oedema; ocular disease diagnosis and treatment.

\section{Introduction}

Non-arteritic anterior ischaemic optic neuropathy (NA-AION) is a vision-threatening disease that is caused by infarction of the short posterior ciliary arteries that supply the optic nerve head $(\mathrm{ONH}){ }^{1,2}$ Non-arteritic anterior ischaemic optic neuropathy is a common cause of acute or subacute optic neuropathy that results in sudden unilateral vision loss in people usually over the age of 50 years. ${ }^{3,4}$ It is the second most common cause of permanent optic nerve-related vision loss in adults after glaucoma. ${ }^{2,5}$

The annual incidence of NA-AION amongst people of European descent in the United States aged above 50 years was estimated at 2.3-10.2 cases per 100000 population. ${ }^{6,7}$ However, the annual incidence in a large Medicare database study ${ }^{7,8}$ was as high as 82 cases per 100000 population, with an annual prevalence of $0.3 \% .7,9$ The Beijing Eye Study estimated the prevalence of NA-AION at 1 in 45000 in a population aged above 40 years. ${ }^{7,9}$ At the time of writing this report, no previous reports on NA-AION in African countries, including South Africa, were found in the literature.

A patient with NA-AION usually presents with acute unilateral vision loss, which some patients describe as a sudden or transient dimming or blurring of vision especially around the central area of the visual field (VF) ${ }^{2,5}$ Peripheral VF defects can also occur as a result of factors such as optic disc oedema. The early clinical findings of NA-AION include sector or diffuse hyperaemic optic disc oedema with or without retinal and/or optic disc haemorrhages. ${ }^{1,2,10}$

Correct diagnosis and proper management of this condition are important to minimise the risk of recurrence and involvement also in the unaffected eye.

\section{Case presentation and special investigations}

A 56-year-old man initially visited the author's practice in 2012 for a routine eye examination to get new spectacles. He reported that his general health was good and that he was not using any medication. Slit-lamp examination did not reveal any abnormalities of the external structures of the eyes. The pupillary response to light was normal on the right eye but slow and reduced in the left eye. The author performed a swinging flashlight test to rule out relative afferent pupillary defect (RAPD), which is the hallmark of unilateral optic neuropathy or retinal disease. ${ }^{11}$ When the light beam was shined on the patient's right eye, both pupils constricted normally (at the same rate and amount). However, when the beam was shined onto the left eye, there was a reduced direct response in that eye and reduced consensual response in the right eye, suggesting RAPD in the left eye.

Non-contact tonometry showed $13 \mathrm{mmHg}$ and $16 \mathrm{mmHg}$, respectively, for the right and left eyes. Direct ophthalmoscopy revealed a small optic disc with a cup-to-disc (C/D) ratio of 0.3 in the 
right eye, and because of diffuse disc oedema, the author could not estimate the C/D ratio in the left eye. Uncorrected visual acuity (VA) measurements for the right and left eyes were $6 / 7.5$ and $6 / 18$, respectively. Optical correction improved VA to $6 / 6$ in the right eye, but no improvement was noted in the left eye.

\section{Differential diagnosis and risk factors}

Non-arteritic anterior ischaemic optic neuropathy must be differentiated from other anterior optic neuropathies, including anterior optic neuritis (idiopathic, demyelinating, sarcoid-related, etc.), anterior compressive optic neuropathy (from anterior orbital lesions) and infiltrative optic neuropathy. ${ }^{5}$ Optic neuritis may resemble NA-AION in terms of the rate of onset, pattern of VF loss and the appearance of the optic disc. However, the presence of ocular pain especially with eye movements, hyperaemic optic disc oedema (without haemorrhages), early recovery and the fact that optic neuritis mostly affects younger patients, distinguishes this condition from NA-AION. ${ }^{5,12}$ Contrary to NA-AION, which presents with acute unilateral vision loss and an optic disc oedema that tends to result in sectoral or diffuse optic nerve atrophy usually within 6-11 weeks after the onset of vision loss, orbital lesion and infiltrative optic neuropathy present with gradual progressive vision loss and optic disc oedema that persist beyond 6-11 weeks. In addition, optic neuropathy from orbital lesion is associated with mild ptosis and abnormal lid and eye movements.

It is of the utmost importance to differentiate NA-AION from arteritic anterior ischaemic optic neuropathy (A-AION), as the two can be easily confused. The primary differentiating factors are prodromal symptoms and the appearance of optic disc oedema. ${ }^{13}$ Arteritic anterior ischaemic optic neuropathy is a disease of the elderly and late middle-aged persons ${ }^{14}$ and typically presents with pain, jaw claudication, scalp tenderness, fever and malaise. ${ }^{2,13}$ Arteritic anterior ischaemic optic neuropathy is characterised by chalky white papilledema and in the majority of cases, when the oedema has resolved the optic disc shows cupping like that of glaucoma (except that there is pallor of the neuroretinal rim in A-AION and no pallor of the neuroretinal rim in glaucoma). ${ }^{15,16}$ On the contrary, NA-AION affects slightly younger patients over 50 years of age $\mathrm{e}^{2,8,14}$ and is typically painless and characterised by severe optic disc oedema with haemorrhages. ${ }^{17}$ The glaucoma-like cupping is not seen in NA-AION. ${ }^{14}$ Furthermore, the prognosis for untreated $\mathrm{A}-\mathrm{AION}$ is quite poor and could lead to rapid blindness, making the differentiation of A-AION and NA-AION paramount. ${ }^{13}$

Non-arteritic anterior ischaemic optic neuropathy is associated with several risk factors, including advanced age, 'disc at risk' (a small C/D ratio or an absent physiologic cup) and common systemic vascular risk factors, such as hypertension, diabetes mellitus, hyperlipidaemia, obstructive sleep apnoea, smoking, migraine, drugs and various coagulopathies. ${ }^{18,19}$ In addition, bilateral optic disc drusen and moderate-to-severe obstructive sleep apnoea in patients non-compliant with continuous positive airway pressure treatment were found to be significant risk factors for the fellow eye involvement in NA-AION. ${ }^{20}$

\section{Treatment, outcomes and follow-up}

The patient was referred to an ophthalmologist for further evaluation; however, the patient failed to comply with the recommendation to see an ophthalmologist (see below).

In 2013, the patient revisited the author's practice for vision screening to renew his driver's licence in compliance with Regulation 102 of the National Road Traffic Act 93 of 1996. This regulation requires that any person in South Africa seeking a new driver's licence or renewing their driver's licence needs to undergo a vision screening test. The patient's vision screening results showed the corrected VA of $6 / 6$ for the right eye and $6 / 20$ for the left eye. The author became concerned about the possible further deterioration in VA in the patient's left eye since his previous visit in 2012. The author thus requested the ophthalmologist report from the patient but discovered that the patient had not actually visited the ophthalmologist as advised in 2012 .

The author referred the patient again and emphasised the need for him to see an ophthalmologist. Three days after the consultation, he came back with the medical report, which showed a VA of 6/6 in the right eye and 6/20 in the left eye, the presence of RAPD, an incipient cataract and optic nerve atrophy in the left eye. The Humphrey Visual Field Test for the Central 30-2 thresholds showed that the VF in the right eye was within normal limits (Figure 1), and in the left eye there was an altitudinal defect of inferior hemianopia caused mainly by NA-AION (Figure 2). The computerised tomography (CT) scan report did not show the presence of any masses/tumours. The ophthalmologist did not prescribe any treatment for the patient but advised him to return to his surgery in 6 months for review.

In 2015, the patient revisited the author's practice for a routine examination to get new glasses. His best corrected visual acuities (BCVA) in the right and left eyes were $6 / 6$ and $6 / 18^{+1}$, respectively. The patient visited the ophthalmologist again in 2017 and brought an optical coherence tomography (OCT) scan, which corroborated the presence of left eye optic atrophy (Figure 3) and no atrophy in the right eye (Figure 4). The BCVA in 2017 were the same as they were in 2015, showing that the VA had stabilised.

\section{Discussion}

The pathogenesis of NA-AION remains unclear, although it is thought to result from transient non-perfusion or hypoperfusion of the $\mathrm{ONH}$ circulation, leading to ischaemia. ${ }^{2,14}$ The exact aetiology of the ischaemia is also 


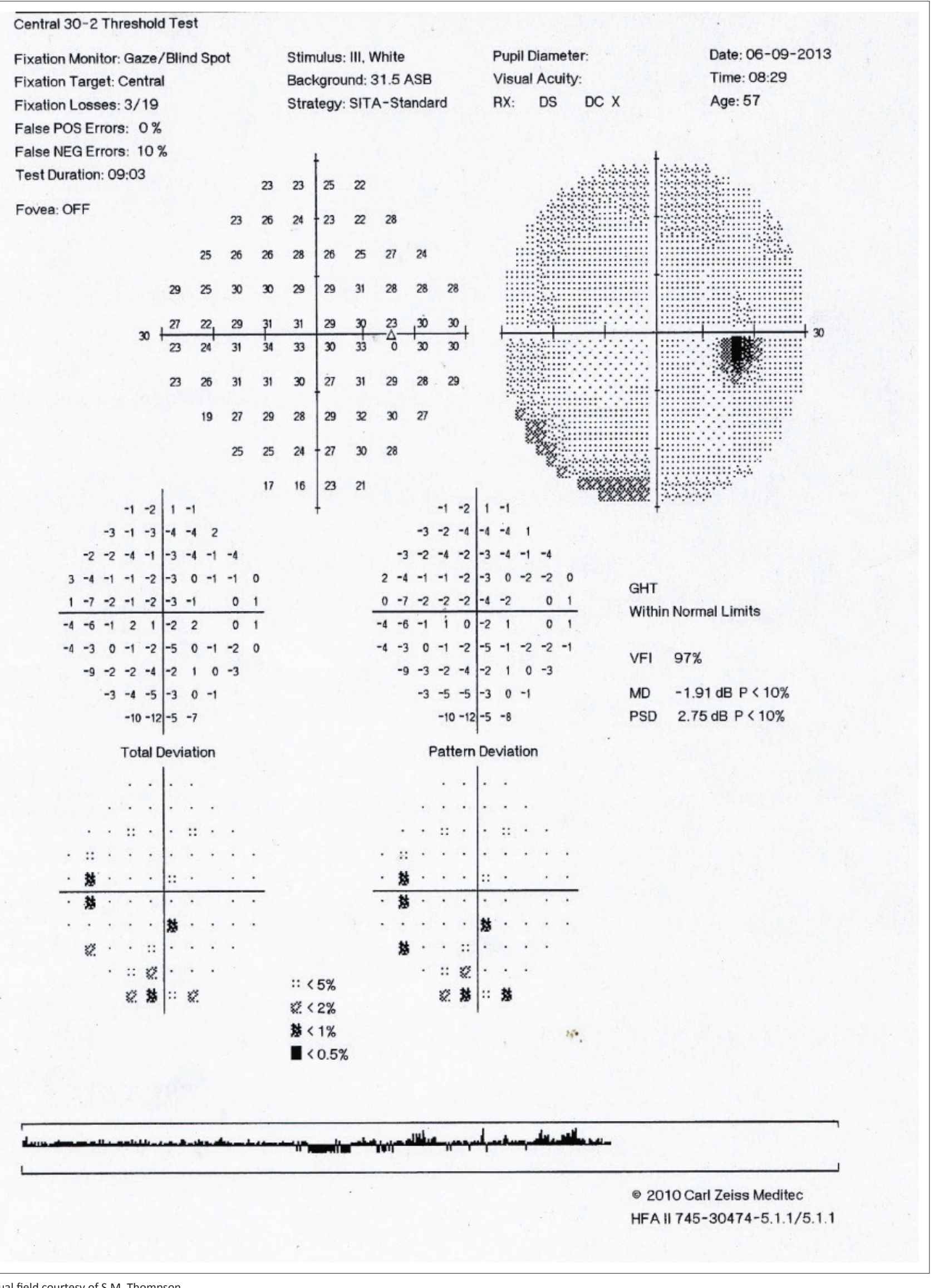

Source: Visual field courtesy of S.M. Thompson

$\mathrm{OD}$, oculus dextrus or right eye; POS, positive; NEG, negative; RX, prescription; DS, dioptre sphere; DC, dioptre cylinder; GHT, glaucoma hemifield test; VFI, visual field index; MD, mean deviation; PSD, pattern standard deviation.

FIGURE 1: Humphrey Visual Field Test (Central 30-2 threshold) showing a normal visual field for the right eye (or OD). 


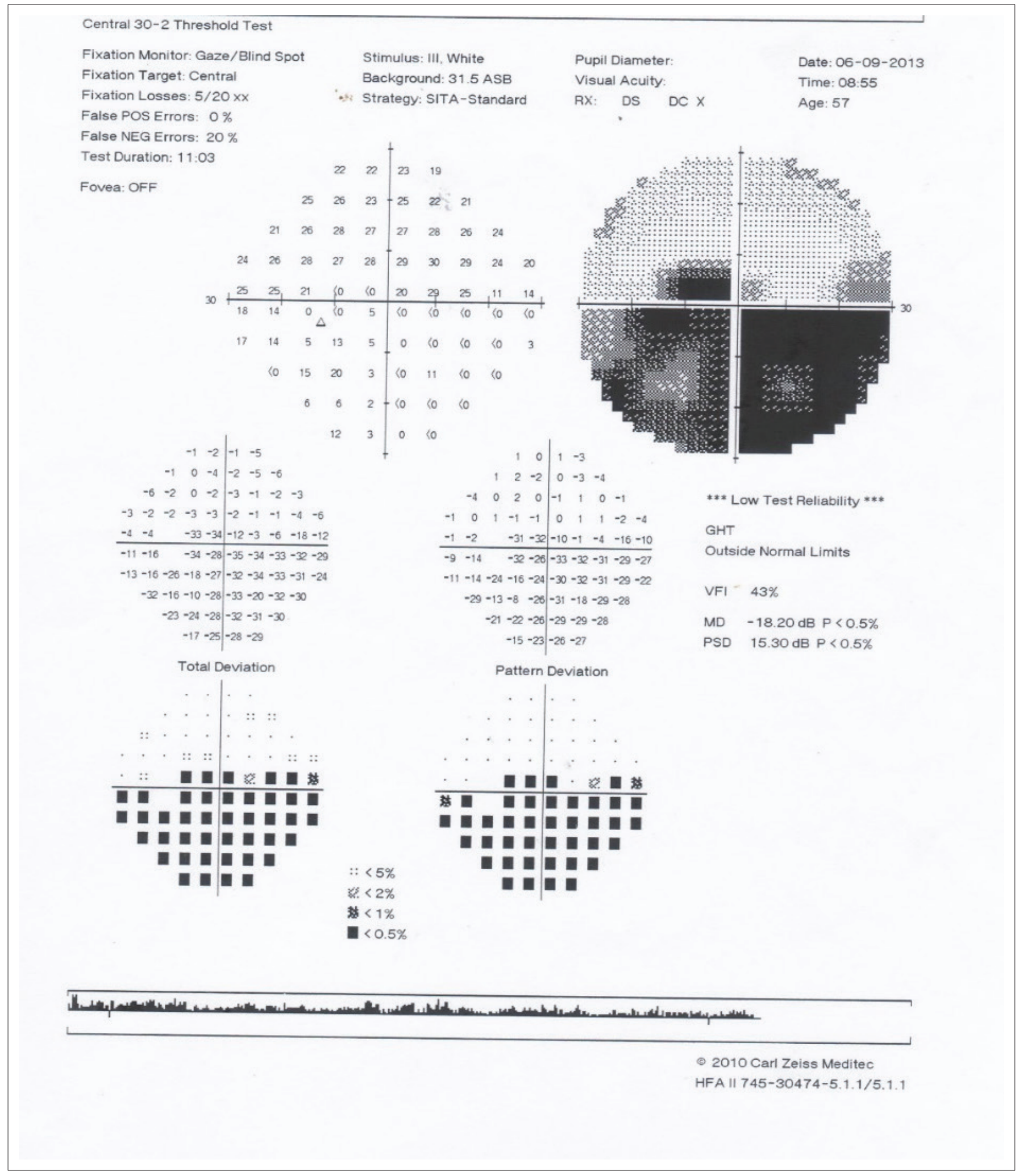

Source: Visual field courtesy of S.M. Thompson

$\mathrm{VF}$, visual field; $\mathrm{OD}$, oculus dextrus or right eye; POS, positive; NEG, negative; RX, prescription; DS, dioptre sphere; $\mathrm{DC}$, dioptre cylinder; GHT, glaucoma hemifield test; $\mathrm{VFI}$, visual field index; $\mathrm{MD}$, mean deviation; PSD, pattern standard deviation.

FIGURE 2: Humphrey Visual Field Test (Central 30-2 threshold) for the left eye suggests a mainly inferior altitudinal or hemi-field visual field defect that might extend even further outwards. Note the result for the fixation losses (5/20), which indicates possible intratest unreliability or difficulties with central fixation or unstable eye movement, possibly because of the visual field loss affecting the foveal or central region of the visual field. The patient might be seeking the vision stimuli by moving the eye about rather than maintaining steady fixation (see also the gaze tracking record below the visual field and compare with OD).

not clear, but several risk factors have been implicated, including arterial hypertension, diabetes mellitus, nocturnal hypotension, ischaemic heart disease, venous occlusion and generalised hypoperfusion..$^{2,14,21}$ In addition, an absent or a small C/D ratio, referred to as a 'disc at risk', has been found to be significantly associated with 


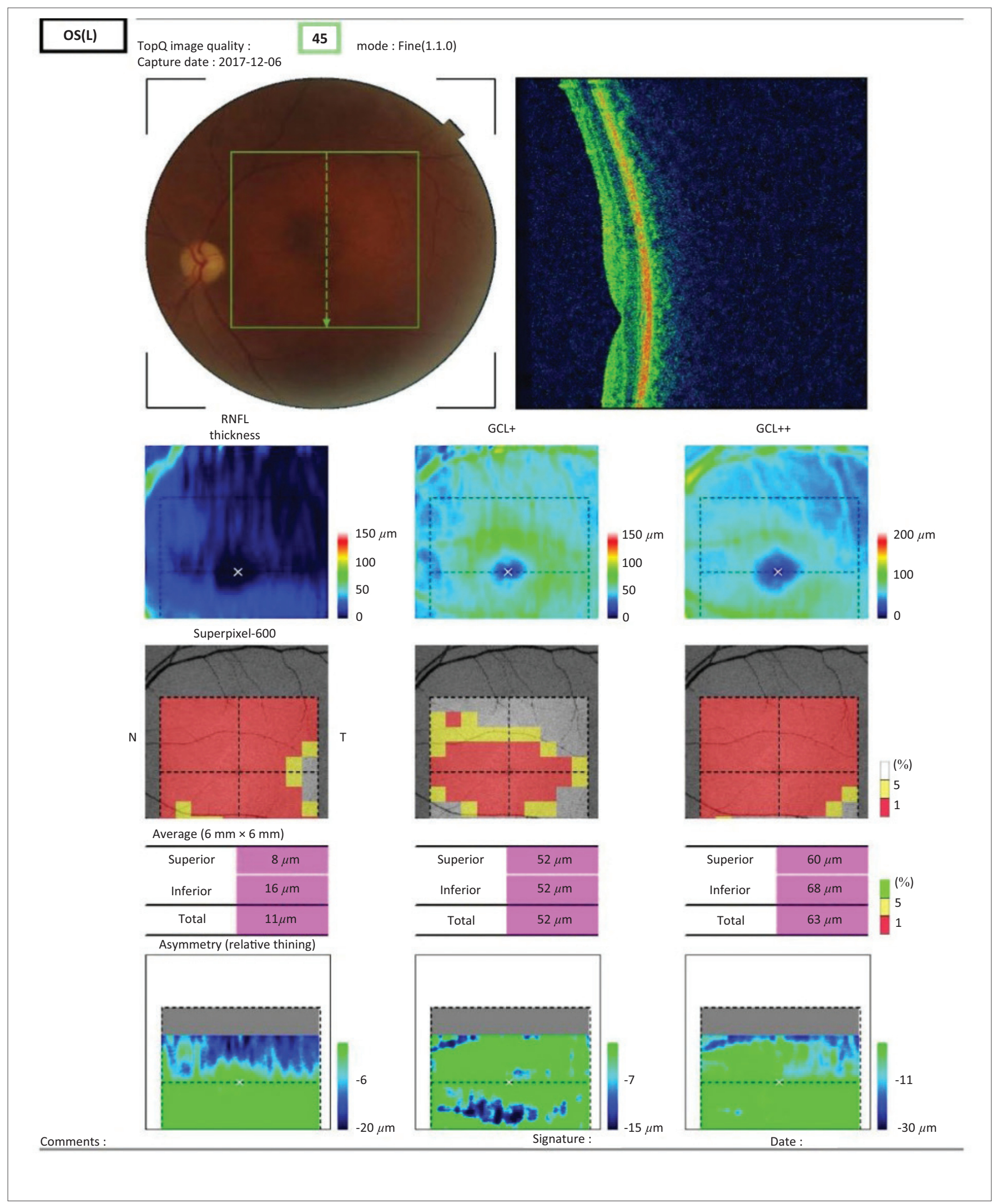

Source: Optical coherence tomography courtesy of S.M. Thompson

$\mathrm{OCT}$, optical coherence tomography; RNFL, retinal nerve fibre layer; $\mathrm{GCL}$, ganglion cell layer.

FIGURE 3: Topcon optical coherence tomography scan for the left eye showing the presence of left eye optic atrophy. The retinal nerve fibre layer and ganglion cell layer are both thinner than expected, suggesting possible retinal nerve fibre layer atrophy.

NA-AION. ${ }^{22}$ Hence, there is a higher prevalence of NA-AION amongst people of European and Asian descent, who generally have smaller optic discs compared with people of African descent., 


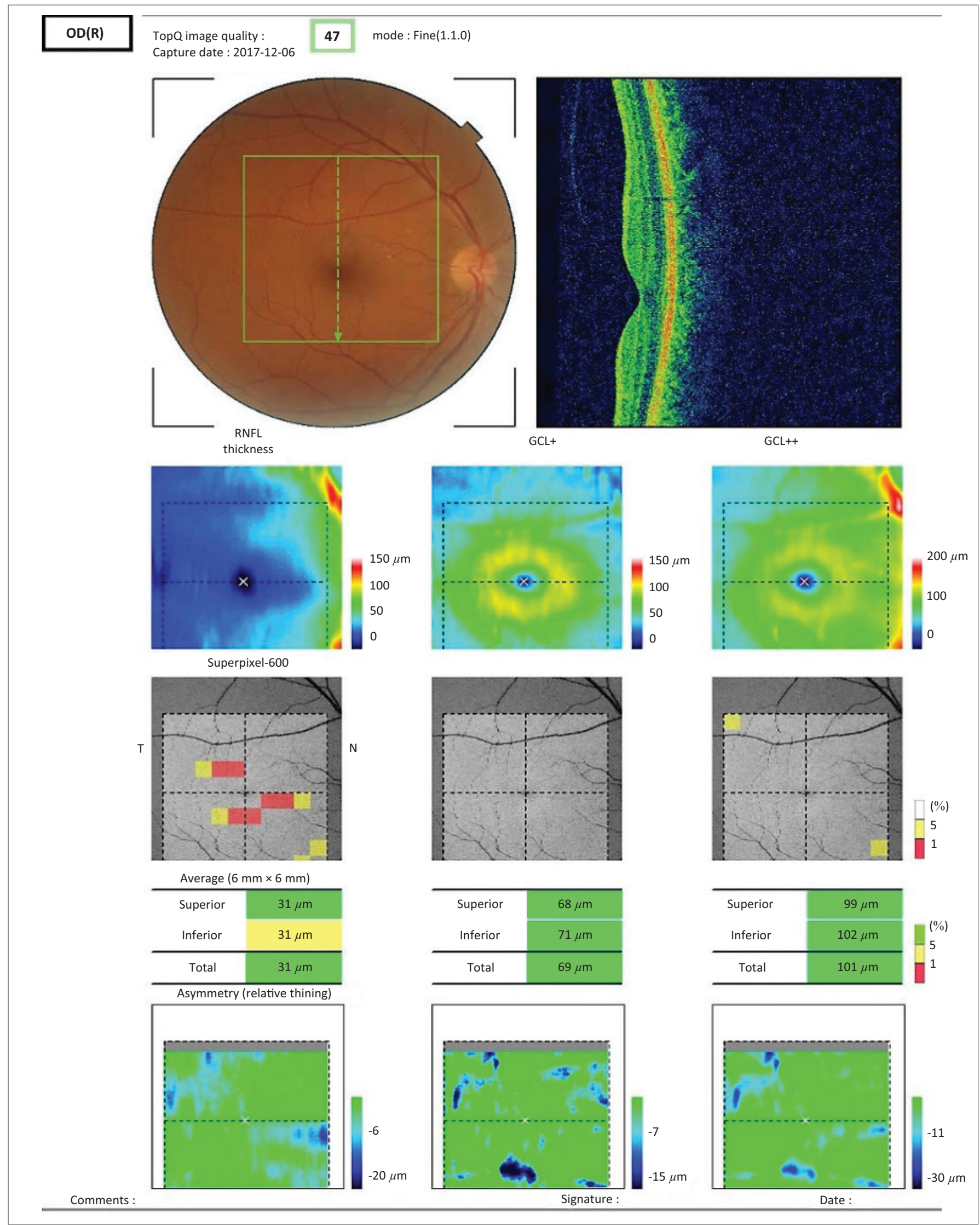

Source: Optical coherence tomography courtesy of S.M. Thompson

$\mathrm{OCT}$, optical coherence tomography; RNFL, retinal nerve fibre layer; $\mathrm{GCL}$, ganglion cell layer.

FIGURE 4: Optical coherence tomography scan for the right eye showing a more normal fundus with a healthier ganglion cell layer. 
The patient in this report did not present with any symptoms of vision loss and supposedly only became aware of the vision loss for the left eye during VA measurements. This was contrary to other reports where patients experienced symptoms of vision loss., ${ }^{2,5}$ Some patients reported experiencing vision loss on awakening. ${ }^{14}$ In a study involving 544 episodes of NA-AION, 51.8\% were symptomatic on awakening, $21.5 \%$ early in the morning and $26.7 \%$ later during the day. ${ }^{1}$ However, this feature was not confirmed in the Ischemic Optic Neuropathy Decompression Trial Study. ${ }^{1,5}$ The vision loss in NA-AION typically progresses over the first 2 weeks ${ }^{1,10}$ and stabilises within 2-3 months, ${ }^{2}$ and there may be an improvement of three or more lines of VA in $13 \%-43 \%$ of the cases after vision loss has stabilised. ${ }^{2,5,10}$

As mentioned above, the early clinical findings of NA-AION include sector or diffuse optic disc oedema with hyperaemia ${ }^{1}$ with or without haemorrhages..$^{1,2,10}$ The oedema tends to result in generalised or sectoral pallor of the optic disc within 4-11 weeks. ${ }^{1,23}$ In 2012, the patient in this report presented with diffuse optic disc oedema in the left eye, and later in 2013 the ophthalmologist's report showed that the left eye had optic nerve atrophy and an incipient cataract. This suggests that when the patient presented to the author's practice in 2012, the NA-AION was still at an early stage (the presence of optic disc oedema vs. optic nerve atrophy), and the cataract in the left eye had not yet developed. The presence of inferior altitudinal VF defects in the patient's left eye is consistent with reports from other authors, ${ }^{2,8,23}$ who reported that the inferior altitudinal and arcuate defects are the most common in NA-AION.

In this case, the ophthalmologist did not prescribe any treatment for the patient but advised him to return to his surgery in 6 months for review, probably because the patient did not present with any symptoms and because the CT scan was normal. Despite the improvement in the understanding of the risk factors and clinical findings, there is no definitive proven treatment for NA-AION. ${ }^{24}$ Several treatments that were advocated in the past, such as surgical decompression of the optic nerve, steroid therapy and aspirin to prevent NA-AION in the fellow eye, were found to be ineffective. ${ }^{14}$

Despite the lack of definitive evidence, many practitioners use aspirin as a treatment for NA-AION and for its role in preventing stroke and coronary artery disease., ${ }^{4,10}$ Patients with NA-AION are usually advised by some ophthalmologists and neurologists that nothing can be done with their condition. ${ }^{14}$ However, Hayreh ${ }^{14}$ believes that such advice is inadequate because NA-AION is a multifactorial disease, with many risk factors contributing to its development. He argues that the correct strategy is to manage the risk factors, especially nocturnal arterial hypotension, to minimise the risk of any further episodes in the affected eye or involvement in the unaffected eye. ${ }^{14}$ Reports have shown that there is a $<5 \%$ chance of recurrence of NA-AION in the affected eye $\mathrm{e}^{2,5}$ and a $15 \%$ chance of involvement in the fellow eye after 5 years. ${ }^{2,22}$ In view of this, optometrists, who are primary eye healthcare providers, could play the role of advising NA-AION patients on better control and management of the vasculopathic risk factors, including smoking cessation, exercise and weight loss to minimise the risk of recurrence in the affected eye and involvement in the fellow eye. ${ }^{14}$

\section{Conclusion}

This report has shown that NA-AION sometimes can occur in patients with apparently no visual symptoms and/or associated risk factors. The clinical signs and symptoms as well as risk factors associated with this condition could help optometrists to take relevant case histories and to perform careful eye examinations to differentially diagnose this condition from other causes of unilateral vision loss such as central retinal artery occlusions, acute angle closure glaucoma, unilateral retinal detachment at or involving the fovea or traumatic ocular injury. Early detection and timely referral potentially could reduce the risk of vision loss in the unaffected eye and recurrence or progression in the affected eye. Further research is required on the epidemiology of NA-AION, especially in the African continent, including South Africa, where data on this condition are lacking.

\section{Acknowledgements}

The author is grateful to S.M. Thompson for his assistance with diagnosis and the optical coherence tomography scans and visual field images.

\section{Competing interests}

The author declares that he has no financial or personal relationships that may have inappropriately influenced him in writing this research article.

\section{Author's contribution}

R.G.M. is the sole author of this article.

\section{Ethical considerations}

A consent letter was taken from the patient to publish the report and anonymity was maintained.

\section{Funding information}

This research received no specific grant from any funding agency in the public, commercial or not-for-profit sectors.

\section{Data availability}

Data sharing is not applicable to this article.

\section{Disclaimer}

The views and opinions expressed in this article are those of the author and do not necessarily reflect the official policy or position of any affiliated agency of the author. 


\section{References}

1. Desai N, Pate MR, Prisant LM, Thomas DA. Nonarteritic anterior ischemic optic neuropathy. J Clin Hypertens. 2007;7(2):130-133. https://doi.org/10.1111/ j.1524-6175.2005.04095.x

2. Berry S, Lin WV, Sadaka A, Lee AG. Nonarteritic anterior ischemic optic neuropathy: Cause, effect, and management. Eye Brain. 2017;9:23-28. https://doi. org/10.2147/EB.S125311

3. Chen J, Zhu J, Chen L, Hu C, Du Y. Steroids in the treatment of nonarteritic anterior ischemic optic neuropathy: A PRISMA-compliant meta-analysis. Medicine (Baltimore). 2019;98(46):e17861. https://doi.org/10.1097/MD.00000000000 17861

4. Atkins EJ. Nonarteritic anterior ischemic optic neuropathy. Curr Treat Options Neurol. 2011;13(1):92-100. https://doi.org/10.1007/s11940-010-0099-0

5. Miller NR, Arnold AC. Current concepts in the diagnosis, pathogenesis and management of nonarteritic anterior ischaemic optic neuropathy. Eye (Lond). 2015;29(1):65-79. https://doi.org/10.1038/eye.2014.144

6. Johnson LN, Arnold AC. Incidence of nonarteritic and arteritic anterior ischemic optic neuropathy: Population-based study in the state of Missouri and Los Angeles county, California. J Neuro-Ophthalmology. 1994;14(1). https://journals. Iww.com/jneuro-ophthalmology/Fulltext/1994/03000/Incidence_of Nonarteritic_and_Arteritic_Anterior.11.aspx

7. Patil M, Ganger A, Saxena R. Non-arteritic anterior ischemic optic neuropathy (NAION) - A brief review. 2016;6(3):158-163. https://doi.org/10.4236/ojoph. 2016.63022

8. Lee MS, Grossman D, Arnold AC, Sloan FA. Incidence of nonarteritic anterio ischemic optic neuropathy: Increased risk among diabetic patients. Ophthalmology. 2011;118(5):959-963. https://doi.org/10.1016/j.ophtha.2011.01.054

9. Wang $Y, X u L$, Jonas JB. Frequency of non-arteritic anterior ischaemic optic neuropathy in adult Chinese: The Beijing eye study. $\mathrm{Br} J$ Ophthalmol. 2007;91(3):401. https://doi.org/10.1136/bjo.2006.103788

10. Atkins EJ, Bruce BB, Newman NJ, Biousse V. Treatment of nonarteritic anterior ischemic optic neuropathy. Surv Ophthalmol. 2010;55(1):47-63. https://doi. org/10.1016/j.survophthal.2009.06.008

11. Broadway DC. How to test for a relative afferent pupillary defect (RAPD). Community Eye Health [serial online]. 2012 [cited 2019 Dec 20] 25(79-80):58-59. Available from: http://www.ncbi.nlm.nih.gov/pmc/articles/ PMC3588138/
12. Arnold AC, Costa RMS, Dumitrascu OM. The spectrum of optic disc ischemia in patients younger than 50 years (an American Ophthalmological Society thesis).
Trans Am Ophthalmol Soc [serial online]. 2013 [cited 2019 Dec 27];111:93-118. Arans Am Ophthalmol Soc [serial online]. 2013 [cited 2019

13. Luber S, Alweis R. Keeping NAION visual loss: Discriminating urgent versus emergent visual loss in an elderly female. BMJ Case Rep. 2014;2014:bcr2013202262. https://doi.org/10.1136/bcr-2013-202262

14. Hayreh SS. Management of ischemic optic neuropathies. Indian J Ophthalmol. 2011;59(2):123-136. https://doi.org/10.4103/0301-4738.77024

15. Punjabi OS, Tanna AP, Rosenberg MA. Optic disk excavation in nonarteritic anterior ischemic optic neuropathy. J Glaucoma. 2011;20(2):71-73. https://doi. org/10.1097/IJG.0b013e3181dddf5c

16. Hayreh SS, Jonas JB. Optic disc morphology after arteritic anterior ischemic optic neuropathy. Ophthalmology. 2001;108(9):1586-1594. https://doi.org/10.1016/ S0161-6420(01)00649-2

17. Voss E, Raab P, Trebst C, Stangel M. Clinical approach to optic neuritis: Pitfalls, red flags and differential diagnosis. Ther Adv Neurol Disord. 2011;4(2):123-134. https://doi.org/10.1177/1756285611398702

18. Hayreh SS, Zimmerman MB. Nonarteritic anterior ischemic optic neuropathy: Clinical characteristics in diabetic patients versus nondiabetic patients. Ophthalmology. 2008;115(10):1818-1825. https://doi.org/10.1016/j.ophtha.2008.03.032

19. Patil A, Mahesh KV, Prabhat N, et al. Non-arteritic anterior ischaemic optic neuropathy - Myths and misconceptions: Experience from a Tertiary Care Centre in North India. Neuroophthalmology. 2019;44(4):246-254. https://doi.org/10.10 80/01658107.2019.1688356

20. Chang MY, Keltner JL. Risk factors for fellow eye involvement in nonarteritic anterior ischemic optic neuropathy. J Neuro-Ophthalmology. 2019;39(2):147-152. https://doi.org/10.1097/WNO.0000000000000715

21. Hayreh SS, Joos KM, Podhajsky PA, Long CR. Systemic diseases associated with nonarteritic anterior ischemic optic neuropathy Am J Ophthalmol. 1994;118(6):766-780. https://doi.org/10.1016/S0002-9394(14)72557-7

22. Beck RW, Servais GE, Hayreh SS. Anterior ischemic optic neuropathy: IX. Cup-todisc ratio and its role in pathogenesis. Ophthalmology. 1987;94(11):1503-1508. https://doi.org/10.1016/S0161-6420(87)33263-4

23. Espino Barros A, Amram AL, Derham AM, Smith SV, Lee AG. Management of ischemic optic neuropathies. Expert Rev Ophthalmol. 2017;12(2):99-109. https:// doi.org/10.1080/17469899.2017.1291341

24. Foroozan R. New treatments for nonarteritic anterior ischemic optic neuropathy. Neurol Clin. 2017;35(1):1-15. https://doi.org/10.1016/j.ncl.2016.08.003 